\title{
Multiple Impact of Integrated Watershed Management in Low Rainfall Semi-Arid Region: A Case Study from Eastern Rajasthan, India
}

\author{
Prabhakar Pathak*, Anil Kumar Chourasia, Suhas P. Wani, Raghavendra Sudi \\ Resilient Dryland Systems, International Crops Research Institute for the Semi-Arid Tropics (ICRISAT), Hyderabad, India \\ Email: p.pathak@cgiar.org
}

Received November 3, 2012; revised December 3, 2012; accepted December 12, 2012

\begin{abstract}
The agriculture in low rainfall areas of eastern Rajasthan, India is characterized by high risks from drought, degraded natural resources and pervasive poverty, food insecurity and malnutrition. In this region, water is the main limiting factor for upgrading rainfed agriculture. For such areas integrated watershed management is recognized as a potential approach for agriculture growth and rehabilitation of fragile and degraded lands. At Gokulpura-Goverdhanpura village in Bundi eastern Rajasthan, India an integrated watershed project was implemented using the holistic systems approach. This paper discusses the impacts of this watershed program on bio-physical, socio-economic, environmental and ecological parameters. Results indicate that due to watershed interventions the groundwater availability has substantially increased which brought changes in cropping patterns with high value crops. Significant increases in irrigated area, cropping intensity along with diversification of crops from traditional to commercial cash crops were recorded. The watershed program also significantly improved the socio-economic status of the watershed community. It has increased the income and reduced poverty of the people in the watershed. The watershed interventions generated good employment opportunities and significantly reduced the migration of both skilled and unskilled labor from the watershed village to urban areas. It has also improved the environmental quality and ecological status in the watershed. The watershed interventions increased the vegetative index or greenery, reduced runoff, soil loss, and land degradations and improved the bio-diversity in fragile ecosystems. Overall, the integrated watershed program at Gokulpura-Goverdhanpura provided resilience by ensuring continued and sustainable multiple outputs, besides soil and water conservation and other positive environmental effects.
\end{abstract}

Keywords: Groundwater Management; Bio-Physical Impact; Socio-Economic Impact; Environmental and Ecological Impact; Semi-Arid Tropics

\section{Introduction}

In most of the SAT (semi-arid tropics) regions, increasing population pressure, lack of investment and technological progress are taking heavy toll on the quality of productive natural resource base. Water scarcity, land degradation and productivity loss are major challenges to the eradication of poverty. Depletion of the resource base diminishes the capacity of the smallholder farmers to earn their livelihood and makes them more vulnerable to drought and other natural disasters.

The rainfed areas of eastern Rajasthan in India are characterized by very low and erratic rainfall, frequent droughts; and agricultural production is uncertain and risky on the degraded soils and depleted water resource. Due to these adverse conditions, agricultural productivity

"Corresponding author. and farmers' incomes are low and highly variable. The area is under-developed and is home to sizeable unemployed, poverty-stricken, and undernourished population. The majority of the population in the region is dependent on agriculture as a source of livelihood. In this harsh environment, water is the most critical resource and a major constraint to improve agricultural productivity. The groundwater which is the main source of water for irrigation and drinking is fast declining. To improve groundwater and to sustain agricultural productivity, effective management and efficient utilization of rainwater is essential [1]. For these regions, integrated watershed management has been proposed and adopted to address the issues related to sustainable agricultural productivity at enhanced level, conservation of soil and water to provide improved livelihood opportunities to farmers [2].

In the past, several studies had been conducted to de- 
termine the impact of integrated watershed programs on agricultural productivity and farmers' livelihoods [3-8]. Most of these studies reported multiple benefits from the integrated watershed program in terms of water availability, soil loss, agricultural productivity, income and environmental and ecological status $[9,10]$. In the past, most of studies focused on assessing biophysical, socioeconomic or environmental effects. The studies covering the impact of integrated watershed program on all the three major aspects related to biophysical, socio-economic and environmental quality in the SAT regions are indeed limited [11]. The objective of this paper is to report on effects of integrated watershed program on biophysical, socio-economic, environmental and ecological changes at the watershed level in low rainfall areas of eastern Rajasthan, India. Therefore, paper focuses on watershed impacts on groundwater recharge and availability, irrigated area, crops and cropping systems, productivity and production of major crops, crop diversification and yield gaps, poverty and income status, food security, livestock production and ruminants, employment opportunities and migration of population, runoff and soil loss, vegetation cover, land degradation and biodiversity.

\section{Materials and Methods}

\subsection{Watershed Details}

The study was undertaken in the Gokulpura-Goverdhanpura watershed situated in Hindoli Tehsil of Bundi district, southeastern part of Rajasthan, India. The watershed is located about $40 \mathrm{~km}$ northwest of Bundi town and lies between latitude $25^{\circ} 35^{\prime} \mathrm{N}$ and longitude $75^{\circ} 25^{\prime} \mathrm{E}$. (Figure 1) with total area of 1355 ha. The topography of the watershed is undulating with $1 \%-15 \%$ slope. The watershed has several small drains (Figure 1) that drains runoff water in the sub-basin of Blandi river. The mean annual rainfall at the Gokulpura-Goverdhanpura watershed is $461 \mathrm{~mm}$ with extreme variation in the annual rainfall. During 1996-2008, the annual rainfall varied from $240 \mathrm{~mm}$ in 1998 to $605 \mathrm{~mm}$ in 2001 .

The soils at watershed are shallow to medium deep with sandy loam to silty loam in texture. The structure of soils is poor due to intensive cultivation and low clay and organic matter status. The soil moisture holding capacity is very low. The soils are deficient in extractable (available) sulphur (S), zinc (Zn), boron (B), and organic C.

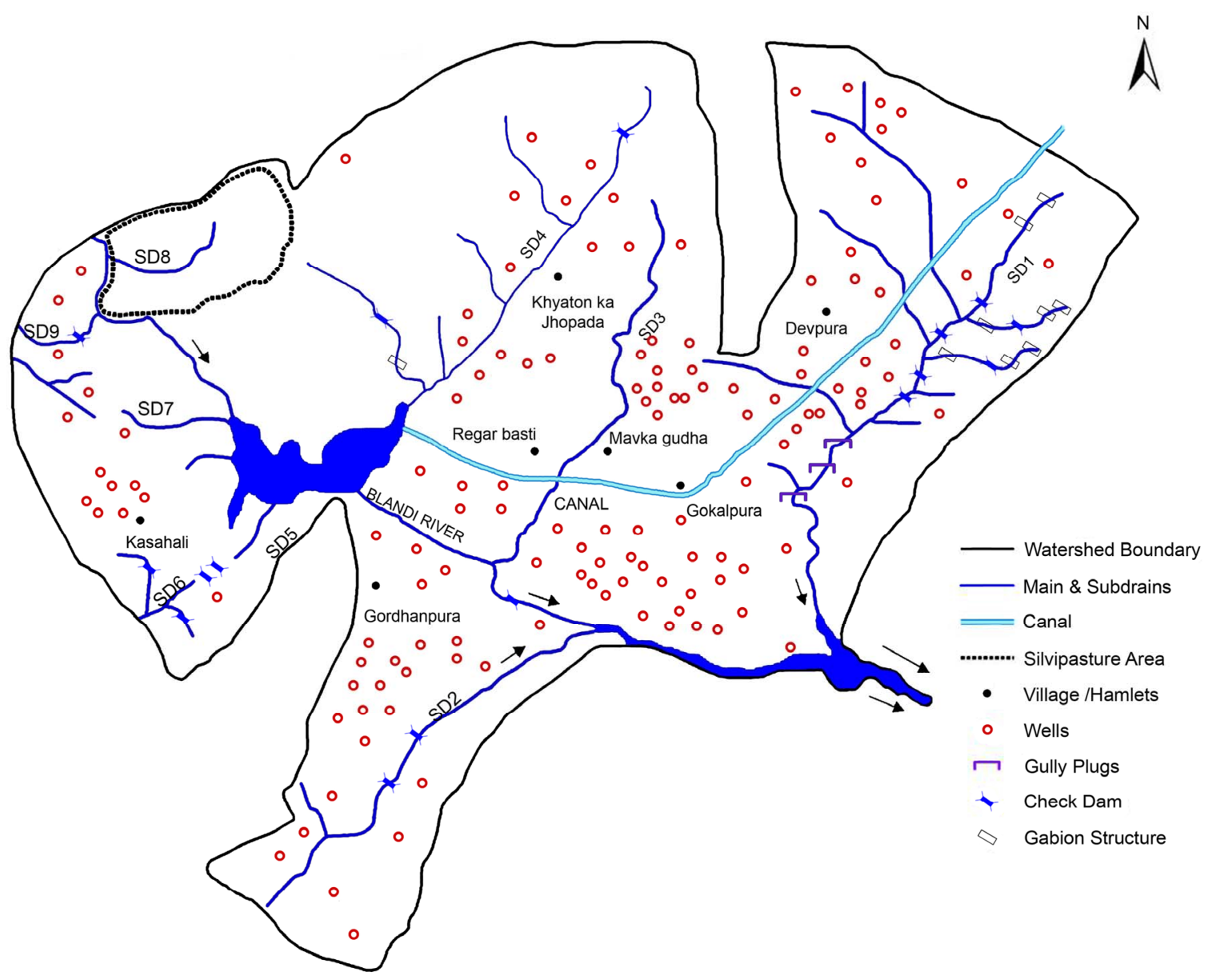

Figure 1. Map of the Gokulpura-Goverdhanpura watershed, Bundi, Rajasthan, India. 
The main source of irrigation and drinking water to watershed villages is from groundwater through open wells. Out of total watershed area of 1355 ha, arable area in the watershed is 701 ha. Summer cultivation is marginal whereas rainy and post-rainy season cultivation with irrigation constitutes a large component of agriculture land use. The major crops grown in the watershed include maize, sorghum, sesame, gaur, wheat, black gram, mustard, chickpea, and vegetables. Common lands are perhaps the most neglected and mismanaged portion of the landscape because of poor mechanisms of management. The Gokulpura-Goverdhanpura villages, as per the baseline survey in 1997, had a population of 1882 , comprising of 334 families with a sex ratio of $55 \%$ men to $45 \%$ women. Average family size was 5.7 persons. The 334 households in the watershed comprised of 152 marginal, 125 small, 36 medium and 21 large landholding families; there were no landless families $[12,13]$.

\subsection{Development of Watershed}

The development of the Gokulpura-Goverdhanpura watershed started in 1997. During its first phase (19972001), the focus of the watershed program was on increasing water availability and controlling soil erosion mainly through water harvesting and groundwater recharging structures. During the second phase (2002$2005)$, the focus was on reducing land degradation; and on improving the food security and livelihoods of the community in the watershed. A range of activities were undertaken including collection and analysis of baseline data; construction of water harvesting and groundwater recharging structures (check dams, percolation tanks, etc.); use of more efficient irrigation system; construction of drainage line treatments (gully plugs, loose boulder structures and gabions); use of improved agronomic practices (improved varieties, nutrient management options, and improved implements), cultivation of high value crops (horticulture and vegetables); silvipasture development on common lands; cattle improvement programs; income generating micro-enterprises for improving the incomes of women and institution building for sustaining the impact of watershed program. All activities were implemented with full participation of the watershed community.

\subsection{Data Collection and Analysis}

During the study, primary as well as secondary data were collected from the Gokulpura-Goverdhanpura watershed. During 2005-2006, the primary data were collected following focus group discussion as well as through stratified detailed household survey. The multi-disciplinary team visited watershed villages and conducted meetings with farmers followed by field visits to collect primary information on general agriculture, crops and their productivity, surface and groundwater and socio-economic data. This was collected through investigation of farmers with pre-tested questionnaires; and about $20 \%$ households/farmers were selected using a stratified random sampling method. The data were personally collected through interviews with farmers. However, before conducting survey, the objectives of the study were explained to farmers. The secondary data were collected from various sources like reports prepared by the implementing agencies. Financial details about the various activities were also collected from project implementing agency. Wherever necessary the topographic surveys were done to supplement the existing data. To monitor the changes in surface and groundwater, groundwater level in the open wells was measured; rainfall and runoff measurements were made at regular intervals. The data were analyzed using statistical techniques such as regression, correlation and coefficient variance analysis.

\section{Results and Discussions}

The basic goal of watershed management is to increase water availability, reduce rural poverty and improve livelihood security, while protecting the environment and enhancing sustainability of natural resources. The Gokulpura-Goverdhanpura watershed was used as a case study for assessing the on-site impact of various watershed interventions implemented to support sustainable agricultural development. Impacts of watershed interventions on biophysical, socio-economic, environmental and ecological changes in the watershed are discussed.

\subsection{Bio-Physical Indicators}

The impact of integrated watershed on groundwater recharge, land use pattern, crops and cropping systems, area productivity and production of major crops and crop diversification are discussed here.

\subsubsection{Groundwater Recharge and Its Availability}

One of the major impacts of the integrated watershed management program was on improving groundwater recharge and its availability. Due to various in-situ and ex-situ soil and water management and other watershed interventions, there was significant increase in groundwater levels (Figure 2). The groundwater level in wells in treated areas of watershed was higher compared to that in untreated areas. This trend in groundwater level was observed during the entire period of the study (20022008). Even during low rainfall years (2003 and 2005), groundwater levels in treated areas were higher than untreated areas of the watershed.

Despite $8 \%$ increase in the number of wells (227 vs. 
248 open wells during pre- and post-watershed period), there is substantial improvement in the performance of open wells (Table 1). There is more than three times increase in the mean pumping duration, substantial improvement in water recovery or recharge period and about three-fold increase in area irrigated by wells due to watershed interventions. Even during the post-rainy and summer seasons, the performance of open wells improved substantially after the watershed program. For example during the post-rainy season, the average area irrigated by each open well increased from 0.5 to 1.4 ha due to watershed interventions (Table 1). More details about the groundwater recharge and its availability during the pre and post-watershed interventions can be explained by the status of water column and duration of water availability in open wells (Figures 3 and 4). In Gokulpura-Goverdhanpura watershed, there was an increase of $52 \%$ in the wells functioning during $4-8$ months in a year, and $114 \%$ increase was observed in perennially functioning of wells (8 - 12 months in a year). Before watershed program, 52 wells out of 227 wells were functional only for $1-4$ months per year mainly during rainy season, whereas after the watershed program, all the 52 wells were functional for $4-8$ or $8-12$ months per year (Figure 3). The mean depth of water level in the wells before the watershed program was $4.5 \mathrm{~m}$ compared to $9.5 \mathrm{~m}$ after the watershed interventions (Figure 3). There is a substantial increase in the mean groundwater level during all the season viz. rainy, post-rainy and summer after the watershed interventions, particularly during post-rainy season when the depth of groundwater column in wells has increased seven folds (Figure 4).

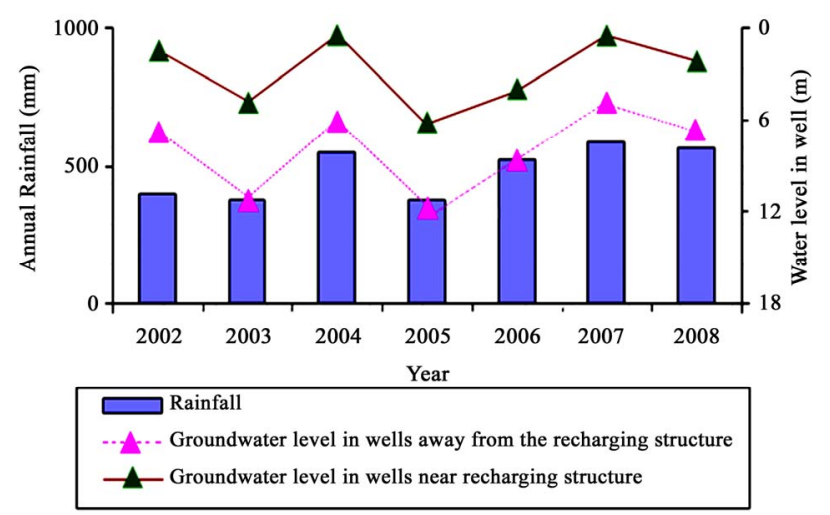

Figure 2. Effects of groundwater recharging structures on mean groundwater level in open wells, Gokulpura-Goverdhanpura watershed, Bundi, Rajasthan India, 2002-2008.

Table 1. Effects of watershed interventions on the performance of open wells at Gokulpura-Goverdhanpura watershed, Rajasthan, India.

\begin{tabular}{|c|c|c|c|c|c|c|}
\hline \multirow{2}{*}{ Season } & \multicolumn{2}{|c|}{ Pumping duration (h) } & \multicolumn{2}{|c|}{ Recharge/recovery period in well (h) } & \multicolumn{2}{|c|}{ Area irrigated by each well (ha) } \\
\hline & BWI $^{*}$ & AWI $^{*}$ & BWI & AWI & BWI & AWI \\
\hline Rainy & 4.0 & 11.0 & 13.5 & 10.0 & 1.0 & 2.5 \\
\hline Post-rainy & 1.5 & 6.5 & 21.0 & 16.0 & 0.5 & 1.5 \\
\hline Summer & 0.0 & 1.0 & 0.0 & 21.0 & 0.0 & 0.2 \\
\hline Mean & 1.8 & 6.2 & 17.3 & 15.7 & 0.5 & 1.4 \\
\hline
\end{tabular}

*BWI is before watershed interventions and AWI is after watershed interventions.

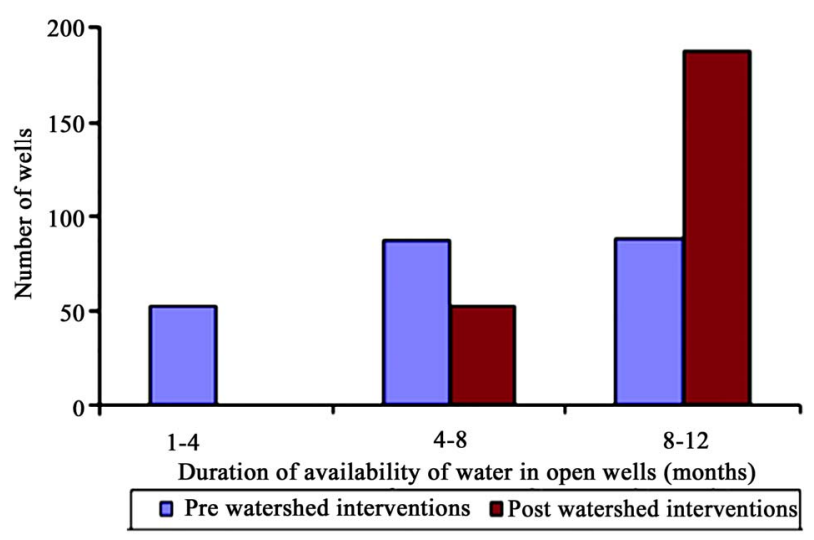

Figure 3. Duration of water availability in open wells in preand post-watershed, interventions periods at GokulpuraGoverdhanpura watershed Rajasthan, India.

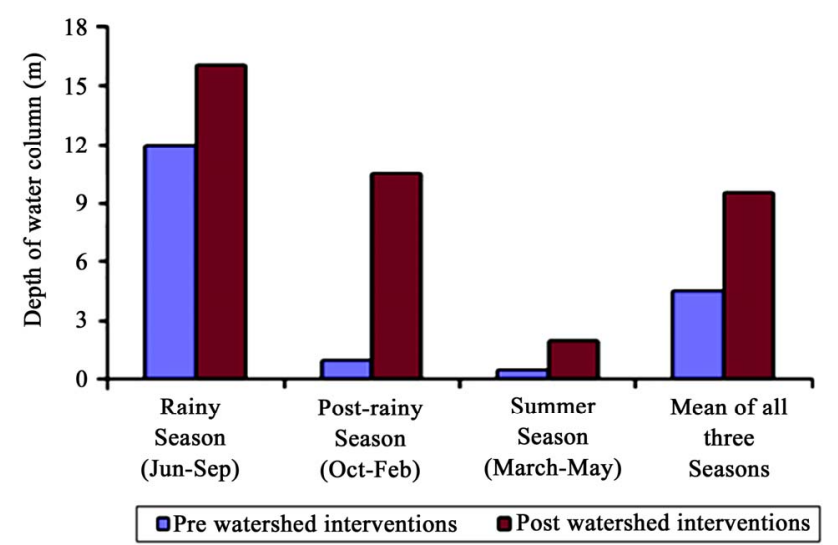

Figure 4. Depth of water column in open wells during different cropping seasons at Gokulpura-Goverdhanpura watershed,Rajasthan, India. 
These data clearly show that the watershed intervenetions brought large increase in groundwater recharge and availability. Increased water availability led to increased investment by farmers to use improved irrigation equipment. This further encouraged farmers to use improved crop varieties in cropping systems, and the cultivation of high value crops.

\subsubsection{Land Use Pattern, Crops, and Cropping Systems}

Increased availability of surface and groundwater significantly changed the land use pattern in the watershed area (Table 2). The total irrigated area increased by $66 \%$ (207 to 343 ha). Importantly, the area under rainfed cropping declined by $36 \%$ (327 to 209 ha). This resulted in marked reduction in crop failure in the watershed area and gave greater confidence to farmers to use improved agricultural inputs viz. fertilizer, improved varieties and other inputs. In addition, about 35 ha area was brought under horticulture. Before watershed program, there was no area under horticulture. This indicates that the increased surface and groundwater availability significantly contributed in increasing irrigated area as well growing horticulture, vegetables and other high value crops that are more profitable.

Due to various watershed interventions, the crops and cropping patterns in the watershed area changed during all the cropping seasons. After the watershed interventions, there is a significant increase in the cultivation of high value crops viz. vegetable (11 to 22 ha) and horticultural crops (nil to 35 ha). After the introduction of watershed program, farmers cultivated new crops like pigeonpea, groundnut, green gram, pearl millet and soybean in the rainy season and green pea and vegetables in post-rainy season. The area under maize increased by $15.8 \%$ (133 to $154 \mathrm{ha}$ ) and under vegetables by $100 \%$ (3 to 6 ha) during rainy season. In the post-rainy season,the area under wheat and chickpea increased by $7.7 \%$ and $28 \%$, respectively. During the post-rainy and summer seasons the area under vegetables and fodder increased by several folds.

\subsubsection{Growth Rate of Area, Productivity and Production of Major Crops}

Due to increased water availability and its efficient utilization along with other interventions increased growth rate of productivity resulting increase in area and production of major crops. The trend in cropped area, productivity and production of important crops during the period of watershed program (1997-2006) in the village is shown in Table 3 . The estimated compound growth rate of area of all major crops increased substantially. The highest growth rate was observed in the case of vegetables followed by chickpea and maize. The compound growth rate of productivity (yield) is higher than growth rate in area. The production of these crops increased because of increase in productivity and area during project period. The diversification towards vegetables is mainly due to increased irrigation water availability and expected higher income.

Table 2. The changes in land use pattern at Gokulpura-Goverdhanpura watershed, Bundi during 1997-2006.

\begin{tabular}{lccc}
\hline \multicolumn{1}{c}{ Land use system } & Before watershed interventions area (ha) & After watershed interventions area (ha) & Change (\%) \\
\hline Irrigated & 207 & 343 & 66 \\
Rainfed & 327 & 209 & -36 \\
Pasture & 167 & 114 & -32 \\
Horticulture & Nil & 35 & 0 \\
Forest & 360 & 360 & 0 \\
Dwelling and river & 294 & 294 & 1355 \\
Total & 1355 & & \\
\hline
\end{tabular}

Table 3. Compound growth rate of area, productivity and production of major crops over the period (1997 to 2006) at Gokulpura-Goverdhanpura watershed, Bundi, Rajasthan, India.

\begin{tabular}{cccc}
\hline \multirow{2}{*}{ Crops } & \multicolumn{3}{c}{ Compound growth rate } \\
\cline { 2 - 4 } & Area & Productivity & Production \\
\hline Maize & 1.85 & 14.18 & 12.75 \\
Wheat & 0.93 & 8.11 & 9.12 \\
Mustard & 0.25 & 6.05 & 6.32 \\
Chickpea & 3.13 & 6.59 & 9.63 \\
Vegetables & 9.05 & 7.99 & 25.59 \\
\hline
\end{tabular}




\subsubsection{Crop Diversification and Yield Gap}

In a harsh climate of eastern Rajasthan where GokulpuraGoverdhanpura watershed is located, the crop diversification is strongly recommended. Crop diversification not only provides a wider choice in production of various crops but also minimizes the risk and increases profitability besides harnessing the potential of land, water, human and climate. The various interventions changed the crops and cropping pattern in the watershed. Many of the small and medium farmers have moved towards cultivating more remunerative pigeonpea, groundnut, green gram and soybean crops. Various factors like increased availability of irrigation water, institutional and infrastructural development, adoption of integrated soil, water and nutrient management technologies, availability of improved varieties and micro-financing etc., are indeed responsible for the changes in crops and cropping systems. Improved skills and awareness also aided diversification of high value crops like vegetables. During watershed program about 35 ha land was planted to various horticultural crops such as mango, guava, lemon, sapota, orange, jackfruit, amla, karonda, ber and custard apple.

To measure the extent of yield gap, the average productivity of important crops in the district was compared with the average productivity of same crops in the watershed (Figure 5). For most of the crops, high yield gap was observed during all cropping seasons. For the rainy season crops, the yield gap varied from 52\% to $213 \%$. During the rainy season, the highest yield gap was found in case of black gram $(213 \%)$ followed by maize $(151 \%)$ and vegetables $(81 \%)$. In the post-rainy season, wheat has the highest yield gap (124\%) followed by mustard $(88 \%)$, lentil $(80 \%)$ and rapeseed (75\%). The crop yield gap during the summer season was relatively less. In the summer, mostly vegetables and fodder crops are grown under irrigation. These data clearly show that the water- shed program is effective in increasing the crop yields; and the yield levels for most of the crops are much higher than the district average yields.

\subsubsection{Livestock Production and Ruminants}

At the Gokulpura-Goverdhanpura watershed, livestock and ruminants are very important component of farming systems. Before the watershed program, most of livestock and ruminants in the watershed villages were of local breed; and their productivity was low. To improve the breed, artificial insemination was undertaken with the help of trained persons. Substantial increase was noticed in the number of cows with marginal (44\%) and small (77\%) farmers (Table 4). Small farmers owning buffaloes had seen $41 \%$ rise, followed by $27 \%$ rise in case of medium holding farmers. A substantial increase in daily milk production from 2.5 to 4.0 liters per animal was achieved. This reflected in increased income, besides improving the nutritional value of food intake of families. In the case of other animals like goat and sheep, a satisfactory increase ( $9 \%$ to $17 \%$ ) was recorded in all categories of farmers. In the village, the number of bullocks increased during the period of watershed program, which indicated that the farmers still prefer using bullocks for the farming purposes. The results from poultry farming were also encouraging and an increase was observed during the watershed program.

\subsection{Socio-Economic Indicators}

Socio-economic indicators are one of the most important parameters used to assess the overall impact of watershed program. The data collected from the Gokulpura-Goverdhanpura watershed on few socio-economic indicators viz. poverty and household income, food security, employment opportunities and labor migration are discussed below.

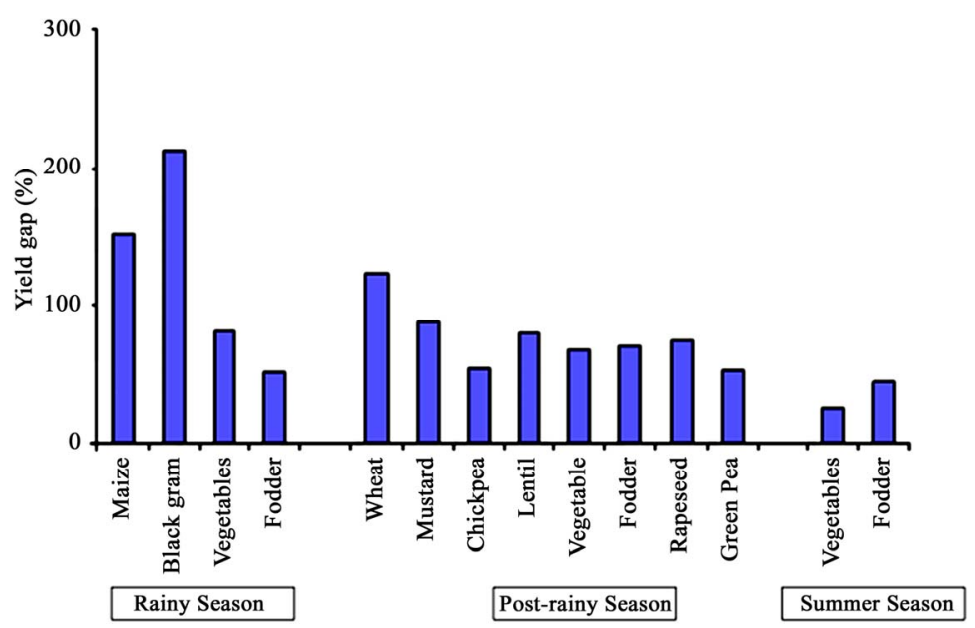

Figure 5. Gaps in crop yields between district average and that in the watershed villages in Bundi, Rajasthan, India (19972005). 


\subsubsection{Poverty Status}

The results on the selected poverty indicators evaluated during the pre and post watershed program clearly indicate that the farmers belonging to marginal and small land holdings got relatively higher benefits from the watershed development activities (Table 5). The head count ratio (which is proportion of population below poverty line) in case of marginal and small farmers fell from 0.13 to 0.006 , and 0.09 to 0.04 , respectively. The depth of poverty gap index also came down in all categories of farmers, resulting in an overall declining in squared poverty gap (which indicates the severity of poverty). After the watershed interventions, the head count ratio among all categories of farmers declined significantly; and in case of large farmers, it was only 0.005 , which indicates that the proportion of population below poverty line is very low. The index of poverty gap in case of marginal and small farmers declined more sharply as compared to that in the case of medium and large farmers. The substantial reduction in all the three poverty indicators could be attributed to successful implementation of the watershed program.

\subsubsection{Food Security}

The parameter to measure food security in the village is based on food availability, accessibility and acceptability. The watershed activities enhanced the productivity of crops and to some extent mitigated the adverse impact of drought thereby provided better food security to families. The per capita availability of food grains and vegetables increased significantly (Figure 6). Over the period, the per capita availability of cereals increased from 90 to 140 $\mathrm{kg}(56 \%)$, while the availability of pulses increased from 30 to $40 \mathrm{~kg}(33 \%)$ per annum. The production of vegetables prior to the watershed program was very low but with increased availability of water and other infrastructural changes, the per capita availability of vegetables increased from 10 to $50 \mathrm{~kg}$ per annum (Figure 6).

\subsubsection{Creation of Employment Opportunities, and Migration of Population}

The watershed program increased the employment opportunities for all categories of farmers due to various activities related to agriculture, horticulture, floriculture, afforestation, animal husbandry and small enterprises (Table 6). The soil and water conservation measures like water storage structures, gully control structures, mini percolation pits, gabion structures and others were constructed in the fields, which provided additional job opportunities to the small and marginal farmers.

Table 4. The influence of watershed program on livestock and small ruminant numbers per households at GokulpuraGoverdhanpura watershed, Bundi, Rajasthan, India.

\begin{tabular}{|c|c|c|c|c|c|c|c|c|}
\hline \multirow{3}{*}{ Livestock/small ruminants } & \multicolumn{4}{|c|}{ Pre watershed program } & \multicolumn{4}{|c|}{ Post watershed program } \\
\hline & \multicolumn{8}{|c|}{ Land holding (ha) } \\
\hline & $<1$ & $1-2$ & $2-4$ & $>4$ & $<\mathbf{1}$ & $1-2$ & $2-4$ & $>4$ \\
\hline Cow & 0.14 & 0.09 & 0.26 & 0.32 & 0.17 & 0.15 & 0.28 & 0.36 \\
\hline Buffalo & 0.08 & 0.10 & 0.17 & 0.25 & 0.08 & 0.12 & 0.19 & 0.24 \\
\hline Goat & 0.23 & 0.18 & 0.09 & 0.07 & 0.22 & 0.17 & 0.09 & 0.08 \\
\hline Sheep & 0.16 & 0.22 & 0.10 & 0.06 & 0.16 & 0.23 & 0.11 & 0.06 \\
\hline Bullocks & 0.18 & 0.23 & 0.12 & 0.09 & 0.16 & 0.21 & 0.12 & 0.09 \\
\hline Poultry birds & 0.46 & 0.36 & 0.21 & 0.15 & 0.64 & 0.47 & 0.27 & 0.17 \\
\hline
\end{tabular}

Table 5. Poverty indices* during pre- and post- watershed intervention in Gokulpura-Goverdhanpura villages, Bundi, Rajasthan, India.

\begin{tabular}{|c|c|c|c|c|c|c|c|c|c|}
\hline \multirow{3}{*}{ Indicators } & \multicolumn{5}{|c|}{ Pre watershed interventions } & \multicolumn{4}{|c|}{ Post watershed interventions } \\
\hline & \multicolumn{9}{|c|}{ Land holdings (ha) ${ }^{*}$} \\
\hline & Reflection & $<1$ & $1-2$ & $2-4$ & $>4$ & $<1$ & $1-2$ & $2-4$ & $>4$ \\
\hline No. of household & & 152 & 125 & 36 & 21 & 208 & 173 & 23 & 14 \\
\hline Head count ratio & Incidence & 0.13 & 0.09 & 0.05 & 0.03 & 0.006 & 0.04 & 0.03 & 0.01 \\
\hline Poverty gap index & Depth & 0.065 & 0.048 & 0.028 & 0.014 & 0.024 & 0.014 & 0.007 & 0.001 \\
\hline Square poverty gap Index & Severity & 0.034 & 0.023 & 0.009 & 0.002 & 0.010 & 0.005 & 0.001 & 0.00 \\
\hline
\end{tabular}

*Farmers category based on land holdings: Marginal $=<1$ ha; Small $=1-2$ ha; Medium $=2-4$ ha; Large $=>4$ ha. 


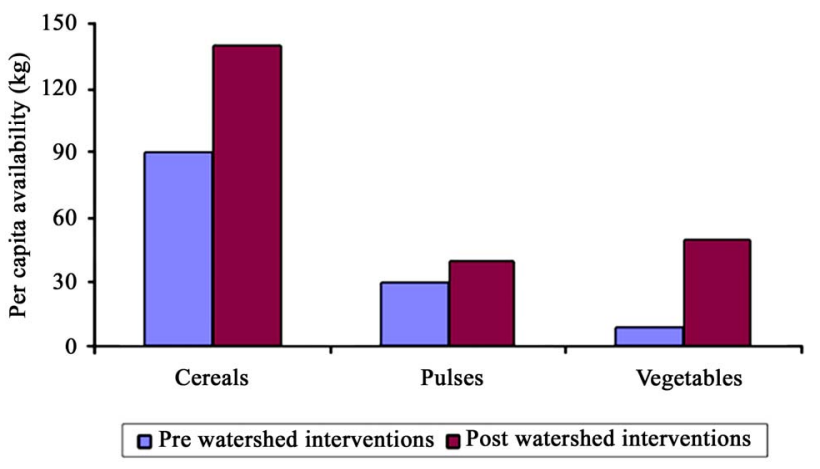

Figure 6. Effects of watershed program on the per capita availability of food grains and vegetables, Gokulpura-Goverdhanpura villages, Bundi, Rajasthan, India.

In case of agriculture, the working days of small and marginal farmers increased by $43 \%$ and $20 \%$ respectively. Floriculture is new activity in the area and provides additional employment to medium and large farmers. Introduction of afforestation has become important source of income, especially for marginal and small farmers; and it provides at least 24-man day's employment in a year. Animal husbandry also supports the livelihoods of poor farmers; and is one of the best ways to generating addi- tional income. During watershed program, the working days of small farmers increased substantially (50\%), while the declining trends were noticed in case of large farmers.

The migration from rural to urban areas is one of the major issues in this region. The Gokulpura-Goverdhanpura watershed achieved good success in reducing the overall migration from rural to urban areas by providing additional employment opportunities to the farmers in the village itself (Table 7). In the watershed villages, both the seasonal and long-term migrations were significantly reduced due to watershed program. Great decline was noticed in seasonal as well as long-term migration, and the decline rate was greater in the case of farmers with large holding, followed by medium landholder farmers. However, a sharp decline was noticed in all categories of farmers in the long-term migration as compared to seasonal migration. The data also suggests that the seasonal as well as long-term migration of skilled labor in all categories of farmers were more reduced as against to the unskilled labor. Interestingly, the percentage of reduction of migration was lower in case of marginal and small holding farmers as compared to medium and large landholder farmers.

Table 6. Employment opportunities (man days per annum) at the Gokulpura-Goverdhanpura watershed, Bundi, Rajasthan, India.

\begin{tabular}{|c|c|c|c|c|c|c|c|c|}
\hline \multirow{3}{*}{ Activities } & \multicolumn{4}{|c|}{ Before watershed program } & \multicolumn{4}{|c|}{ During watershed program } \\
\hline & \multicolumn{8}{|c|}{ Land holdings (ha) } \\
\hline & $<1$ & $1-2$ & $<2-4$ & $>4$ & $<1$ & $1-2$ & $<2-4$ & $>4$ \\
\hline Agriculture & 84 & 120 & 120 & 144 & 120 & 144 & 132 & 156 \\
\hline Horticulture & Nil & Nil & Nil & Nil & 36 & 36 & 60 & 72 \\
\hline Floriculture & 0 & 0 & 12 & 12 & 24 & 24 & 36 & 24 \\
\hline Afforestation & 12 & 0 & 24 & 24 & 24 & 24 & 12 & 24 \\
\hline Animal husbandry & 36 & 24 & 36 & 24 & 48 & 36 & 24 & 12 \\
\hline \multicolumn{9}{|l|}{ Small enterprises } \\
\hline Agriculture based & 12 & 12 & 24 & 36 & 12 & 12 & 24 & 36 \\
\hline Non-agriculture based & 24 & 24 & 12 & 12 & 24 & 24 & 12 & 12 \\
\hline Others & 12 & 12 & 12 & 12 & 12 & 12 & 12 & 12 \\
\hline Total & 180 & 192 & 240 & 264 & 312 & 348 & 336 & 360 \\
\hline
\end{tabular}

Table 7. Migration status as affected by the implementation of watershed program at the Gokulpura-Goverdhanpura watershed, Bundi, Rajasthan, India.

\begin{tabular}{|c|c|c|c|c|c|c|c|c|}
\hline \multirow{3}{*}{ Nature of work } & \multicolumn{4}{|c|}{ Pre watershed program } & \multicolumn{4}{|c|}{ Post watershed program } \\
\hline & \multicolumn{8}{|c|}{ Land holdings (ha) } \\
\hline & $<1$ & $1-2$ & $<2-4$ & $>4$ & $<1$ & $1-2$ & $<2-4$ & $>4$ \\
\hline \multicolumn{9}{|c|}{ Seasonal migration (persons per annum) } \\
\hline Skilled labor & 25 & 18 & 10 & 7 & 7 & 5 & 3 & 1 \\
\hline Unskilled labor & 62 & 43 & 15 & 14 & 21 & 18 & 8 & 2 \\
\hline Skilled labor & 5 & 2 & 1 & 1 & 2 & 1 & 1 & 0 \\
\hline Unskilled labor & 12 & 5 & 3 & 1 & 3 & 5 & 1 & 1 \\
\hline
\end{tabular}




\subsection{Environmental and Ecological Effects of Watershed Interventions}

During the watershed program, several measures were undertaken to minimize runoff, soil loss, land degradation, and to improve surface and groundwater resources, vegetative cover or greenery and other ecological factors. Increased water availability resulting in increased cropping intensity, use of improved crops and cropping systems and other improved inputs, afforestation, plantation of horticulture plants, rehabilitation of degraded common lands through silvipasture systems and several other watershed interventions resulted in reduced runoff, soil loss, sedimentation and siltation of surface water bodies. The remote sensing image taken before and during the watershed program shows the impact of watershed interventions in improving the vegetative cover (Figure 7). Due to watershed interventions, the annual runoff from the watershed is reduced by $52 \%$ and soil loss by $64 \%$. This indicates that the watershed program is effective in conserving rainwater and controlling soil erosion, thereby minimizing land degradation.

Over grazing, over exploitation and other anthropogenic factors resulted in severe problems of degradation of common lands. To combat this hazard and maintain ecological balance, watershed development program implemented a management system for the rehabilitation of common land and biodiversity development through silvipasture systems managed by the local communities. This system converted the degraded wasteland in to valuable and beneficial asset for community. The number of useful species of grasses and fodder increased. Several local plants, shrubs and bushes viz. Dhokara (Anogeis- suslatifolia), Khejari (Prosopis cineraria), Desi Babul (Acacia nilotica), Neem (Azadirachta indica), Palas (Buteamonosperma), Salur and Ber bush regenerated in the common lands besides the flora and fauna were rehabilitated in this area. Silvipastoral practices help in the conservation of vegetation, soil and nutrients and provide forage, fuel and timber on sustainable basis to the community.

\section{Conclusion}

The integrated watershed management program at the Gokulpura-Goverdhanpura watershed made significant positive impact on water resources, rural livelihoods and environment and ecology. The major impact of watershed program was on improved surface and groundwater availability even during the critical periods of post-rainy and summer seasons. Increased surface and groundwater availability resulted in increased cropping intensity and diversification to more remunerative land use systems involving livestock, horticultural and vegetable production. Watershed program increased the productivity of most of the crops, resulting in higher profit margin. It also significantly decreased the adverse impact of drought and provided more food, water and fodder security to the community. Due to watershed activities, the livestock population and their productivity increased substantially particularly in the case of the marginal and small farmers. The socio-economic status of population significantly improved due to the impact of watershed program. The watershed program also increased the income and reduced poverty of people in the watershed. The small and marginal farmers got relatively greater benefits from the

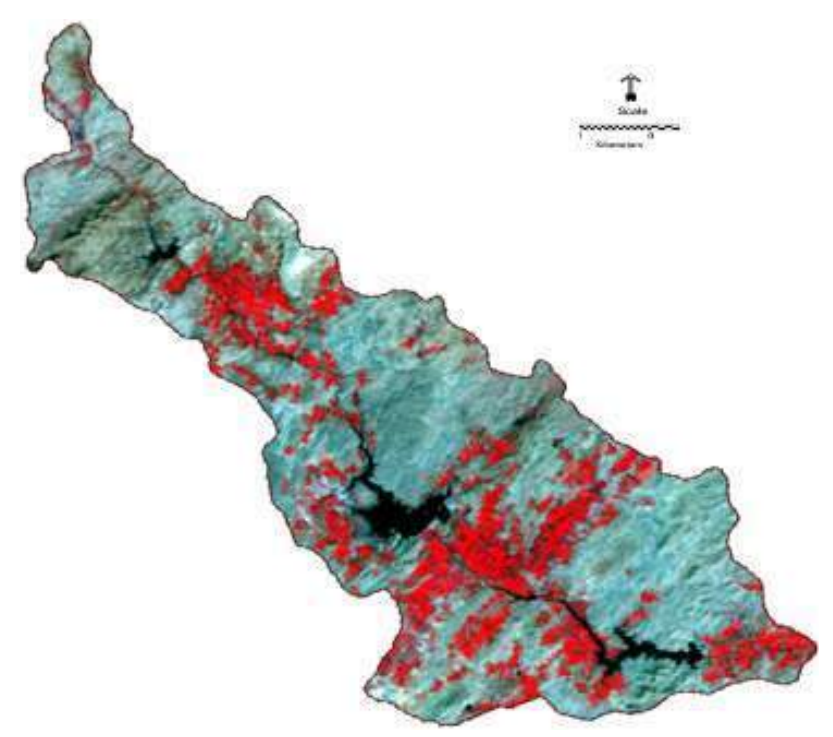

(a) Before watershed Program

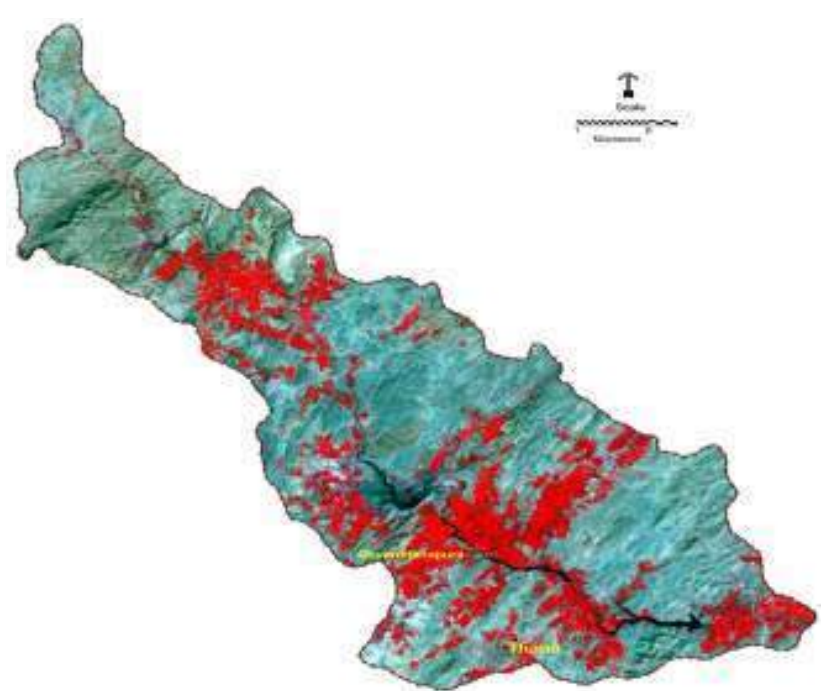

(b) During watershed Program

Figure 7. Remote sensing images showing the vegetative cover at the treated parts of the Gokulpura-Goverdhanpura watershed before and during watershed program. 
watershed activities. It increased the working days of all categories of farmer; and achieved good success in reducing the seasonal as well as long-term migration from rural to urban areas by providing better employment opportunities to farmers within the village itself. In summary the watershed program improved surface and groundwater resources, minimized land degradation, reduced runoff and soil loss, enhanced vegetative cover and improved ecological status; and finally brought prosperity to the people in the watershed villages.

\section{Acknowledgements}

This publication is a part of research project "combating land degradation and increasing productivity in Madhya Pradesh and Eastern Rajasthan, India" supported by Sir Dorabji Tata Trust. We acknowledge the BAIF Development Research Foundation, Bundi, Rajasthan for their key support to the project. We are thankful to Mr. T. P. Mathur and Mr. Gedam for facilitating the work covered in this report. The authors are highly thankful to Dr. K. L. Sahrawat and Mr. B. Nagaraju for their inputs in improving the manuscript.

\section{REFERENCES}

[1] J. Rockström, L. Karlberg, S. P. Wani, J. Barron, N. Hatibu, T. Oweis, A. Bruggeman, J. Farahani and Z. Qiang, "Managing Water in Rain-Fed Agriculture-The Need for a Paradigm Shift," Agricultural Water Management, Vol. 97, No. 4, 2010, pp. 543-550.

[2] Government of India, "Common Guidelines for Watershed Development Projects," Department of Land Resources, Ministry of Rural Development, Government of India, New Delhi, 2008.

[3] K. Chopra, G. K. Kadekodi and M. N. Murthy, "Participatory Development, People and Common Property Resources," Sage Publication, New Delhi, 1990.

[4] R. S. Deshpande and M. N. Murthy, "Watershed Development Approach and Experience of National Watershed Development Program in the Country," Journal of Rural Development, Vol. 18, No. 3, 1999, pp. 453-469.
[5] C. H. Hanumantha Rao, "Watershed Development in India: Recent Experience and Emerging Issues," Economic and Political Weekly, Vol. 35, No. 45, 2000, pp. 3943-3947.

[6] J. Kerr, G. Pangare, L. V. Pangare and P. J. George, “An Evaluation of Dryland Watershed Development Projects in India," EPTD Discussion Paper 68, Environment and Policy Production Technology Division, International Food Policy Research Institute, Washington DC, 2000.

[7] S. P. Wani, K. H. Anantha, T. K. Sreedevi, R. Sudi, S. N. Singh and M. D'Souza, "Assessing the Environmental Benefits of Watershed Development: Evidence from the Indian Semi-Arid Tropics," Journal of Sustainable Watershed Science \& Management, Vol. 1, 2011, pp. 10-20.

[8] V. R. Reddy, "Sustainable Watershed Management: Institutional Perspective," Economic and Political Weekly, Vol. 35, No. 38, 2000, pp. 3435-3444.

[9] P. K. Joshi, A. K. Jha, S. P. Wani, T. K. Sreedevi and F. A. Shaheen, "Impact of Watershed Program and Conditions for Success: A Meta-Analysis Approach," Global Theme on Agro Ecosystems Report No. 46, International Crops Research Institute for the Semi-Arid Tropics, Patancheru 502 324, Andhra Pradesh, 2008, p. 24.

[10] B. Shiferaw, C. Bantilan and S. P. Wani, "Policy and Institutional Issues and Impacts of Integrated Watershed Management: Experiences and Lessons from Asia,” In: B. Shiferaw and K. P. C. Rao, Eds., Integrated Management of Watersheds for Agricultural Diversification and Sustainable Livelihoods in Eastern and Central Africa: Lessons and Experiences from Semi-Arid South Asia, Proceedings of the International Workshop, Nairobi, 6-7 December 2004, pp. 37-52.

[11] K. Palanisami and S. Kumar, "Impact Assessment of Select Watersheds in Coimbatore District of Tamil Nadu," Water Technology Centre, Tamil Nadu Agricultural University, Coimbatore, 2004, p. 80.

[12] R. Verma, M. S. Nadoda and M. Gaur, "BAIF-ICEF Project Base Line Survey Report of Gokulpura-Goverdhanpura Watershed," Hindoli Tehasil, Bundi, 1997.

[13] BAIF-ICEF, "Water Resources Development and Energy Conservation for Sustainable Management of the Environment," Progress of Work 1997-2001, BAIF-ICEF Project, BAIF Divisional Office, Bundi, 2002. 